\title{
Factors that Contribute to Attitudes Towards Professional Psychological Help Seeking for Mental Health Issues Among Teacher Trainees in Kenya
}

\author{
Eunice Jemalel Nyavanga ${ }^{1,2}$ \\ ${ }^{1}$ Department of Social and Human Development, Faculty of Social Sciences and Technology, The Technical University of Kenya, Nairobi, \\ Kenya \\ ${ }^{2}$ Malel-Bibwob Clinical Psychologists Consultancy Limited, Nairobi, Kenya
}

Email address:

enyavanga@yahoo.com, emalel.nyavanga@gmail.com

\section{To cite this article:}

Eunice Jemalel Nyavanga. Factors that Contribute to Attitudes Towards Professional Psychological Help Seeking for Mental Health Issues Among Teacher Trainees in Kenya. American Journal of Applied Psychology. Vol. 6, No. 6, 2017, pp. 142-146.

doi: 10.11648/j.ajap.20170606.11

Received: June 20, 2017; Accepted: August 31, 2017; Published: October 28, 2017

\begin{abstract}
Mental illness including substance abuse disorders is a major concern among college student population, yet nearly half of them have no knowledge on mental health issues. In addition more than half of these students report not to have received any information on mental health or sought any help for a mental illness, causing a great magnitude of health burden. This study aims to determine factors that contribute to attitudes towards professional psychological help seeking for a mental illness. Four colleges out of the existing 20 public primary teacher colleges were conveniently sampled, and all present consenting students were recruited for the study. Two colleges formed the experimental group while the other two formed the experimental group. Baseline assessment using researcher developed demographic questionnaire, with three standardized tools of opinions about mental illness, attitudes towards professional help seeking and expectations about counseling were used to collect data. Psychoeducation was given to the experimental group, and three other evaluations using the same tools were done, one soon after the psychoeducation, third and fourth three and six months after the psychoeducation, The control group only received two other evaluations, soon after baseline and three months after baseline. This study found out that opinions about mental illness, expectations about counseling, psychoeducation, experience in teaching before coming to collage and being female gender contribute significantly to attitudes towards professional psychological help seeking for a mental illness. Main recommendation made is to include mental health education and counseling in teacher training curriculum to improve attitudes to seeking help.
\end{abstract}

Keywords: Attitudes, Teacher Trainees, Mental Health, Opinions, Expectations

\section{Introduction}

College students are characterized by rapid intellectual and social developments. In addition they face situations and circumstances that are a risk for mental illnesses. [1, 2]. Mental illness including substance abuse disorders is a major concern among college student population, yet nearly half of them have no knowledge on mental health issues. [1, 2]. In addition, more than half of these students report not to have received any information on mental health from their college or university, [1]. One out of four people globally are affected by mental health problems in some time in their livers, WHO report, [3] causing a great magnitude of health burden that does not match the size and effectiveness of response demands.

These mental health problems especially alcohol use disorders are common in collage age population [4], and are reported to be increasing significantly, placing a huge burden on health systems, the individual, the family, the college community and the society in general, [5]. Despite the above, most young people are known not to seek help globally, [6-8].

\subsection{Young People Help Seeking Attitudes}

Young people and adolescence have been reported to seek help for physical health care compared to mental health 
problems, [9]. Only $42.8 \%$ of young people with mental health problems seek help from a professional in the last three months among those attending primary health care clinics in the urban cities, [10].

Other studies have indicated that young people have negative attitudes towards professional psychological help seeking globally, [11-14]. Some of the reasons pointed out being negative attitudes towards seeking help for a mental illness problem, $[13,15]$, lack of knowledge on where to seek help, [16], not being able to recognize symptoms due to poor knowledge of mental illness, [17].

Less is known about the contribution of the expectations about counseling, opinions of mental illness and socio demographic characteristics on attitudes about professional psychological help seeking for a mental illness in this region. The aim of this study is to determine factors that contribute to attitudes towards professional psychological help seeking among college students.

\subsection{Importance of Factors That Contribute to Attitudes Towards Help Seeking for Youth}

The prevalence of depression has been found to be high in sub-Sahara Africa, 31.4\% in South Africa, [18]. Furthermore most (57\%) young people between the ages of 18-29 years of age who have been identified with depression do not seek help, [18], part of the reason being lack of knowledge on these illnesses.

\section{Method}

\subsection{Overall Objective}

This study aimed at determining some of the factors that contribute to attitudes towards professional psychological help seeking among college youth in Kenya.

\subsection{Study Design and Sampling}

This study is part of a larger longitudinal quasiexperimental study namely: "The Effects of Psychoeducation on attitudes towards mental health seeking behavior among primary school teacher trainees in Kenya".

Four primary teachers colleges were sampled conveniently from the twenty public colleges. The target population was estimated to be of an average age between 18-42 years. The sampled colleges were estimated to have a population of 3400 students both first and second years, based on Ministry of Education records (Statistics Department). It was learned that recruitment for teacher training was based on a quota system, meaning all parts of the country would be represented. All consenting and present participants were recruited for this study with the aim of increasing generezability of the results.

\subsection{Measures}

Data was collected using researcher-developed selfadministered demographic questionnaire and three standardized instruments of (1) Opinions about Mental
Illness scale (OMI) by Cohen and Struening, 1962, [19], (2) Attitudes toward seeking Professional Psychological Help Seeking Scale-short form (ATSPPHS-BF) by Fisher and Turner, 1970[20] and (3) Expectations about Counseling brief form (EAC-BF) by Tinsley. [21].

\subsection{Ethical Considerations}

The Kenyatta National Hospital and Nairobi University Ethics Committee (KNH/UON-EC) protocol, which sets forth research ethics concerning individual's personal data, was strictly adhered to, in order to ensure confidentiality. With ethical approval, authority and permission was sought from the Ministry of Education and college principals respectively. The purpose, plan and implications of the study were explained before meeting the participants.

\subsection{Procedure for the Study}

These participants were met at the college normal classrooms, where informed consent was sorted, and the measure tools were presented to them while sited in their normal classrooms. The dully-filled forms were sealed and placed at the front into a sealed box. The experimental groups from two colleges were given four measures one at baseline, second soon after psychoeducation, the third fourth three months and ten months after psychoeducation respectively. The control group on the other hand had only three assessments, one at baseline, the second soon after the baseline and the third, three months after baseline assessment.

\subsection{Data Management}

Collected data was double entered into the computer by two clerks separately, and later analyzed using SPSS Version 19.0. The GLM Univariate procedure was used to provide a regression analysis and analysis of variance for attitudes towards help seeking by the demographic factors.

\section{Results}

\section{Participant Demographics}

Table 1. Demographics.

\begin{tabular}{llll}
\hline $\begin{array}{l}\text { Demographic } \\
\text { Characteristic }\end{array}$ & Category & Frequency & Percentage \\
\hline \multirow{2}{*}{ Gender } & Female & 1466 & $52.8 \%$ \\
& Male & 1311 & $47.2 \%$ \\
Age groups & 20 Years and below & 609 & $21.9 \%$ \\
& 21 - 25 Years & 1658 & $59.7 \%$ \\
Year of Study: & Over 25 years & 510 & $18.4 \%$ \\
& 1st Year & 1281 & $46.1 \%$ \\
Previous Teaching & 2nd Year & 1496 & $53.9 \%$ \\
Experience & Yes & 1173 & $42.2 \%$ \\
& No & 1575 & $56.7 \%$ \\
Igrew up in & Other & 29 & $1.0 \%$ \\
& Village & 1604 & $57.8 \%$ \\
\hline
\end{tabular}

Out of the 2777 participants, $52.8 \%$ were female (1466/2777), $59.7 \%$ were between $21-25$ years of age (1658/2777), $21.9 \%$ 
twenty years and below (609/2777), while most, 53.9\% were second years, (1496/2777). Those who had no teaching experience were $56.7 \%(1575 / 22777)$ and those who grew up in the village were the majority $57.8 \%$ (1604/2777).

Table 2. Factors that contribute to the Attitudes towards professional psychological help seeking.

\begin{tabular}{|c|c|c|c|c|c|c|}
\hline \multicolumn{7}{|l|}{ Tests of Between-Subjects Effects } \\
\hline \multicolumn{7}{|c|}{ Dependent Variable: Attitudes towards help seeking } \\
\hline Source & & Type III Sum of Squares & df & Mean Square & $\mathbf{F}$ & Sig. \\
\hline \multirow{2}{*}{ Intercept } & Hypothesis & 13824.989 & 1 & 13824.989 & \multirow{2}{*}{33.701} & \multirow{2}{*}{.072} \\
\hline & Error & 523.217 & 1.275 & $410.226^{\mathrm{a}}$ & & \\
\hline \multirow{2}{*}{ Expectations about Counselling } & Hypothesis & 4972.573 & 1 & 4972.573 & \multirow{2}{*}{162.945} & \multirow{2}{*}{$.000 * *$} \\
\hline & Error & 80045.994 & 2623 & $30.517^{\mathrm{b}}$ & & \\
\hline Opinion about Mental illness & Hypothesis & 1306.851 & 1 & 1306.851 & 42.824 & $.000 * *$ \\
\hline \multirow{2}{*}{$\begin{array}{l}\text { Psychoeducation } \\
\text { (Control/experimental group) }\end{array}$} & Hypothesis & 19259.392 & 1 & 19259.392 & \multirow{2}{*}{631.104} & \multirow{2}{*}{$.000 * *$} \\
\hline & Error & 80045.994 & 2623 & $30.517^{\mathrm{b}}$ & & \\
\hline \multirow{2}{*}{ Previous teaching experience } & Hypothesis & 2007.607 & 1 & 2007.607 & \multirow{2}{*}{65.787} & \multirow{2}{*}{$.000 * *$} \\
\hline & Error & 80045.994 & 2623 & $30.517^{\mathrm{b}}$ & & \\
\hline \multirow{2}{*}{ Gender } & Hypothesis & 1911.286 & 1 & 1911.286 & \multirow{2}{*}{62.630} & \multirow{2}{*}{$.000 * *$} \\
\hline & Error & 80045.994 & 2623 & $30.517^{\mathrm{b}}$ & & \\
\hline a.019 MS (Group) +.004 MS (Q & $+.005 \mathrm{MS}(\mathrm{C}$ & $72 \mathrm{MS}$ (Error) & & & & \\
\hline
\end{tabular}

Expectations about counseling, opinion about mental illness, psychoeducation, previous teaching experience and gender were established to have a significant $(p=0.000)$ contribution to attitudes towards help seeking behaviour for a mental health issue see table 2 above.

\section{Discussion}

\subsection{Expectations About Counseling Contribution to Attitudes Towards Seeking Professional Help Seeking}

This study found that an expectation about counseling is a significant $(\mathrm{p}=0.000)$ contributor to attitudes towards professional psychological help seeking. This means that with a more positive expectations about counseling due to a mental illness, there is likely to increase in attitudes towards professional psychological help seeking. This result is similar to other findings, [22-23]. This is further supported by a study by Scott et al, [24] who reported that males and specifically black males are not likely to seek professional help for psychological problems.

\subsection{Opinions About Mental Illness Contribution to Attitudes Towards Seeking Professional Help Seeking}

This study reported that opinions of mental illness significantly $(p=0.000)$ contributed and predicted attitudes to professional help seeking among these participants. This finding is similar to findings of Wenjing, et al [25] among Australian University students. In addition, a study by Loeng \& Zachar, [26] found out that opinions about mental illness was a significant contributor to attitudes towards mental illness, especially being more benevolent, higher mental hygiene, and being less socially restrictive and less authoritarian.

\subsection{Psychoeducation on Mental illness and Expectations About Counseling Contribution Towards Attitudes to Seeking Help for a Mental Illness}

Psychoeducation significantly $(\mathrm{p}=0.000)$ contributed and predicted attitudes towards professional help seeking among this participants. This is similar to other studies, among college students [27], and the community, [28-30].

\subsection{Previous Teaching Experience Contribution to Attitudes Towards Seeking Professional Help}

Previous teaching experience before coming to college indicated a significant $(\mathrm{P}=0.000)$ contribution towards help seeking among these participants. This is in line with other studies, [31].

\subsection{Gender Contribution on Attitudes Towards Seeking Professional Help Seeking}

Being of the female gender contributes significantly $(p=0.000)$ to favourable attitudes towards professional psychological help seeking among these participants. This is similar to other studies globally among college students and others, [22-23, 31]; although Watson 2014 [32] did not find any significant contribution in gender among young people in Australia.

\section{Conclusion and Recommendations}

This study concludes that opinions about mental illness, expectations about counseling, psychoeducation on mental health and expectations about counseling for a mental illness, previous teaching before coming to college and being of the female gender contribute significantly on attitudes towards professional psychological help seeking for a mental illness among these participants.

The implication is that for college students to improve attitudes towards help seeking, they should get knowledge on mental illness and expectations about counseling for a mental illness. Knowledge on mental illness would be able to make them not only identify the signs and symptoms of mental illness amongst themselves, but among peers and students they are expected to teach in their formal teaching in schools. Knowledge would also make them disminify the cultural 
beliefs of causes, treatment and course of mental illness in the community. Literacy in treatment of mental illness would make them learn to visit psychologists when signs and symptoms arise or refer others for the same. When they know what to expect in counseling it will go a long way to assist in attitude change and seek help. The male gender, may need more than the female gender in changing attitudes for help seeking.

The study recommends the following:

1) The college students should be able to learn that mental illness is rampant at college and should be able to identify signs and symptoms not only in selves but among peers and the students they are going to teach to seek help early.

2) The policy makers, that is the government should increase psychologists in colleges to improve identify mental illnesses, give psychoeducation to improve mental health among the students.

3) The policy implementers, the administration and lecturers should improve the college curriculum by including mental health literacy and counseling classes so that the students will be armed with knowledge to identify mental illness among selves, their peers, and the school community.

4) Other researchers should continue researching on other barriers to professional psychological help seeking for a mental illness in this region, so that we can be able to improve attitudes towards help seeking specifically among the youth.

\section{Acknowledgements}

Acknowledgement to Dr. Muthoni Mathai and Professor DM Ndetei, for supervising this research, and Dr. Linkhon Khasakhala for helping in the development of the concept for this paper, not forgetting the college administration who arranged the modalities of data collection in between their very busy college schedules. Thanks to all the participants for their participation.

This research study was not funded.

\section{References}

[1] Hunt, J., \& Eisenberg, D. (2010). Mental health problems and help-seeking behavior among college students. Journal of Adolescent Health, 46(1), 3-10. DOI: http://dx.doi.org/10.1016/j.jadohealth.2009.08.008

[2] Zivin, K., Eisenberg, D., Gollust, S. E. \& Golberstein, E. (2009). Persistence of mental health problems and needs in a college student population. Journal of Affective Disorders; 117(3): 180-185. https://doi.org/10.1016/j.jad.2009.01.001

[3] WHO, (2002). The World Health Report -Mental Health: New Understanding, New Hope. World Health Report Press Kit.

[4] Blanco, C., Okuda, M., Wright, C., Hasin, D. S., Grant, B. F., Liu, S. M., \& Olfson, M. (2008). Mental health of college students and their non-college-attending peers: results from the national epidemiologic study on alcohol and related conditions. Archives of general psychiatry, 65(12), 1429-1437. doi: 10.1001/archpsyc.65.12.1429

[5] Erskine, H. E., Moffitt, T. E., Copeland, W. E., Costello, E. J., Ferrari, A. J., Patton, G.,. \& Scott, J. G. (2015). A heavy burden on young minds: the global burden of mental and substance use disorders in children and youth. Psychological medicine, 45(7), 1551-1563. DOI: https://doi.org/10.1017/S0033291714002888

[6] Zawawi J. M. A. Psychological Help Seeking Attitudes and Personality factors among Jordanian College Students. European Journal of Social Sciences 2011; 25(4): 606-629.

[7] Chen, R. and Mak, W. Seeking Professional Help: Etiology and beliefs about mental illness across cultures. Journal of Counseling Psychology 2008; 55: 442-450.

[8] Eisenberg, D., Downs, M. F., Golberstein, E., \& Zivin, K. (2009). Stigma and help seeking for mental health among college students. Medical Care Research and Review, 66(5), 522-541.

[9] Marcell, A. V., \& Halpern-Felsher, B. L. (2005). Adolescents' Health Beliefs are critical in their intentions to seek Physical Care; Preventive Medicine; 41(1): 118-125. https://doi.org/10.1016/j.ypmed.2004.10.016

[10] Burnett-Zeigler, I., Walton, M. A., Ilen, M., Barry, K. L., Cermack, S. T., Zuchker, R. A., et al. (2012). Prevalcenc and Corrolatiotes of Mental Health Problems \& Treatment among Adolescence Seen in Primary Care. Journal of Adolescent Health; 50(6): 559-564.

https://doi.org/10.1016/j.jadohealth.2011.10.005

[11] Nyavanga \& Barasa, (2016). Attitudes Towards Professional Psychological Help Seeking Among Young Adults in Kenya: Case Study of Public Teacher Training Colleges. Psychology and Behavioral Sciences; 5(3): 69-76 doi: $10.11648 /$ j.pbs.20160503.12

[12] Essau CA: Frequency and patterns of mental health services utilization among adolescents with anxiety and depressive disorders. Depress Anxiety. 2005, 22 (3): 130-137. 10.1002/da.20115.

[13] Rickwood, D. J., Deane, F. P., \& Wilson, C. J. (2007). When and how do young people seek professional help for mental health problems. Med J Aust, 187(7 Suppl), S35-S39.

[14] Sawyer, M. G., Arney, F. M., Baghurst, P. A., Clark, J. J., Graetz, B. W., Kosky, R. J., \& Rey, J. M. (2001). The mental health of young people in Australia: key findings from the child and adolescent component of the national survey of mental health and well-being. Australian and New Zealand Journal of Psychiatry, 35(6), 806-814.

[15] Mojtabai, R. (2009). Unmet need for treatment of major depression in the United States. Psychiatric Services, 60(3), 297-305.

[16] Fox JC, Blank M, Rovnyak VG, Barnett RY: Barriers to help seeking for mental disorders in a rural impoverished population. Community Ment Health J. 2001, 37 (5): 421-436. 10.1023/A:1017580013197.

[17] Gulliver, A., Griffiths, K. M., \& Christensen, H. (2010). Perceived barriers and facilitators to mental health help seeking in young people: a systematic review. $B M C$ psychiatry, 10(1), 113. 
[18] Andersson, L. M., Schierenbeck, I., Strumpher, J., Krantz, G., Topper, K., Backman, G., \& Van Rooyen, D. (2013). Helpseeking behaviour, barriers to care and experiences of care among persons with depression in Eastern Cape, South Africa. Journal of affective disorders, 151(2), 439-448. https://doi.org/10.1016/j.jad.2013.06.022.

[19] Cohen, J.; Struening, E. L. (1962). Opinions about mental illness in the personnel of two large mental hospitals. The Journal of Abnormal and Social Psychology; 64(5): 349-360. http://dx.doi.org/10.1037/h0045526

[20] Fischer, Edward H.; Turner, John I. (1970). Orientations to seeking professional help: Development and research utility of an attitude scale. Journal of Consulting and Clinical Psychology, 35(1): 79-90. http://dx.doi.org/10.1037/h0029636

[21] Tinsley, H. E. A. (1980). Expectations About CounselingBrief form. Mukilteo, WA: Author.

[22] Shea, M., \& Yeh, C. (2008). Asian American students' cultural values, stigma, and relational self-construal: correlates of attitudes toward professional help seeking. Journal of Mental Health Counseling, 30(2), 157-172.

[23] Nam, S. K., Choi, S. I., Lee, J. H., Lee, M. K., Kim, A. R., \& Lee, S. M. (2013). Psychological factors in college students' attitudes toward seeking professional psychological help: A meta-analysis. Professional Psychology: Research and Practice; 44(1): 37-45. http://dx.doi.org/10.1037/a002956

[24] Scott, L. D., McMillen, J. C., \& Snowden, L. R. (2015). Informal and formal help seeking among older Black male foster care youth and alumni. Journal of child and family studies, 24(2), 264-277. doi: 10.1007/s10826-013-9832-0

[25] Wenjing, L., Denson, L. A., \& Dorstyn, D. S. (2007), Understanding Australian University Students' Mental Health Help-Seeking: An Empirical and Theoretical Investigation: Australian Journal of Psychology, DOI: 10.1111/ajpy.12157.

[26] Leong, F. T., \& Zachar, P. (1999). Gender and opinions about mental illness as predictors of attitudes toward seeking professional psychological help. British Journal of Guidance
\& Counselling, 27(1), 123-

132.http://dx.doi.org/10.1080/03069889908259720

[27] Gonzalez, J. M., Tinsley, H. E. A., \& Kreuder, K. R (2002). Effects of Psychoeducational Interventions on Opinions of Mental Illness, Attitudes toward Help Seeking, and Expectations about Psychotherapy in College Students. Journal of College Student Development; 43(1): 51-63.

[28] Taylor-Rodgers, E., \& Batterham, P. J. (2014). Evaluation of an online psychoeducation intervention to promote mental health help seeking attitudes and intentions among young adults: Randomised controlled trial Journal of Affective Disorders; 168: 65-71. doi: 10.1016/j.jad.2014.06.047.

[29] Hadlaczky, G., Hokby, S., Mkrtchian, A., Carli, V., \& Wasserman, D. (2014). Mental Health First Aid is effective Public Health Intervention for Improving Knowledge, Attitudes and Behavior: A meta-analysis: International Review of Psychiatry. Psychiatry; 26(4): 467-475. DOI: 10.3109/09540261.2014.924910.

[30] Ghafoori, B., \& Korosteleva, O. (2016). A Randomized, Control Pilot Study of a single Psychoeducation Treatment for Urban, Culturally Diverse, Trauma-Exposed Adults, Journal of Nervous and Mental Disease: 204(6): 421-430. J doi: 10.1097/NMD.0000000000000512.

[31] Kokkinos, C. M., \& Stavropoulos, G. (2016). Burning out during practicum: the case of teacher trainees. Educational Psychology: An International Journal of Experimental Educational Psychology; 36(3): 548-568. Doi: $10.1080 / 01443410.2014 .955461$

[32] Komiya, Noboru; Good, Glenn E.; Sherrod, Nancy B. (2000). Emotional openness as a predictor of college students' attitudes toward seeking psychological help. Journal of Counseling Psychology, Vol 47(1), Jan 2000, 138-143. http://dx.doi.org/10.1037/0022-0167.47.1.138

[33] Watsford, C., \& Rickwood, D. (2014). Young people's expectations, preferences, and experiences of therapy: Effects on clinical outcome, service use, and help-seeking intentions. Clinical Psychologist, 18(1), 43-51. DOI: 10.1111/cp.12034 